\title{
Seasonal Influence on Postoperative Complications after Total Knee Arthroplasty
}

\author{
Azeem Tariq Malik, MBBS ${ }^{1}$, Shahid Khan Azmat, MBBS, FCPS ${ }^{2}$, Arif Ali, MBBS², Syed Hamza Mufarrih², and \\ Shahryar Noordin, MBBS, FCPS ${ }^{2}$ \\ ${ }^{1}$ Department of Orthopaedics, The Ohio State University Wexner Medical Center, Columbus, OH, USA; ${ }^{2}$ Section of Orthopaedic Surgery, Department of Surgery, Aga \\ Khan University, Karachi, Pakistan
}

\begin{abstract}
Purpose: This study is aimed at investigating whether inpatient complications and surgical site infections (SSIs) occurred more commonly in patients undergoing total knee arthroplasty (TKA) during the summer season.

Materials and Methods: A total of 725 patients who underwent unilateral or bilateral TKA were included in this study. A total of 241 patients (33.2\%) underwent TKA between May and August. Our outcomes of interest were the incidence of postoperative complications and length of stay. Results: May-August surgeries were associated with a higher risk of postoperative inpatient complications ( $\mathrm{p}=0.003$ ). May-August surgeries (odds ratio $[\mathrm{OR}], 2.13$; 95\% confidence interval [CI], 1.18 to 3.85), postoperative transfusion (OR, 2.46; 95\% CI, 1.43 to 4.26 ), postoperative special care unit stay (OR, 4.68; 95\% CI, 1.99 to 11.0) and chronic kidney disease (OR, 3.27; 95\% CI, 1.15 to 9.28) were associated with a higher odds of developing inpatient complications. No association was present between summer surgeries and SSIs ( $\mathrm{p}=0.486$ ).

Conclusions: The results of this study show that overall complication rates following TKA exhibit a seasonal trend, with a peak during the summer months. These results may have some implication in clinical practice and stricter approaches to hospital guidelines during the summer months.
\end{abstract}

Keywords: Knee, Arthroplasty, Complication, Season

\section{Introduction}

Total knee arthroplasty (TKA) has been widely recognized as the gold standard in the treatment of advanced osteoarthritis of the knee ${ }^{1,2}$. Studies have shown that it successfully results in pain relief and improvement in the functional outcome in greater than $90 \%$ of the patients ${ }^{3}$.

A significant percentage of patients (range, $10 \%$ to $20 \%$ ) however still continue to experience complications and report poor outcomes following this procedure. With the evolution of tech-

Received July 12, 2017; Revised September 7, 2017;

Accepted September 18, 2017

Correspondence to: Azeem Tariq Malik, MBBS

Department of Orthopaedics, The Ohio State University Wexner

Medical Center, Columbus, $\mathrm{OH} 43210$, USA

Tel: +1-773-516-0823

E-mail: azeemtariq94@gmail.com

This is an Open Access article distributed under the terms of the Creative Commons Attribution Non-Commercial License (http://creativecommons.org/licenses/by-nc/4.0/) which permits unrestricted non-commercial use, distribution, and reproduction in any medium, provided the original work is properly cited. nology, recent studies are targeting the identification of factors that contribute to decreasing morbidity and mortality after TKA and bring about cost-effectiveness to both the patient and the hospital.

Previous studies have shown that there is a significant rise in inpatient admissions and adverse events during the summer months $\mathrm{s}^{4,5)}$. Researches have attributed this rise in morbidity during the summer months to various reasons such as the 'July effect' and work-related accidents ${ }^{6}$. The majority of these studies are from the western part of the world, where induction of new trainees and residents takes place at the start of July, and research has shown that an influx of inexperienced trainees and residents brings about an increase in morbidity and mortality (July effect). In our country, the induction of new trainees and residents takes place at the start of the new year (January 1st). Few studies have been conducted examining the influence of seasonal changes on perioperative surgical outcomes, and most of them have been from developed countries where the different climate pattern and abundant resources reflect different results, and these cannot be extrapolated to a developing country such as Pakistan ${ }^{5,7-10)}$. Based 
on the literature review using PubMed (MEDLINE), we were unable to find any study from South Asia investigating the effect of season on postoperative complications. Considering the humid and hot weather of the equatorial countries, we hypothesized that surgeries done during the summer months would have a higher rate of postoperative complications and a significantly longer length of stay.

\section{Materials and Methods}

\section{Patients}

This was a retrospective study done at one of major tertiary care referral hospitals in Pakistan from January 2006 to December 2015. After exemption from the Ethical Review Committee of Aga Khan University, records for all TKAs done within this time period were accessed. All patients, regardless of gender, comorbidities and age, who underwent a unilateral or bilateral TKA were included in the study. Those patients who underwent a revision TKA were excluded from the study. Those patients who had missing data were also excluded from the study. A total of 725 patients were included in the final analysis. Flowchart of data extraction is shown in Fig. 1. TKAs were performed by multiple attending staff surgeons with residents assisting during the

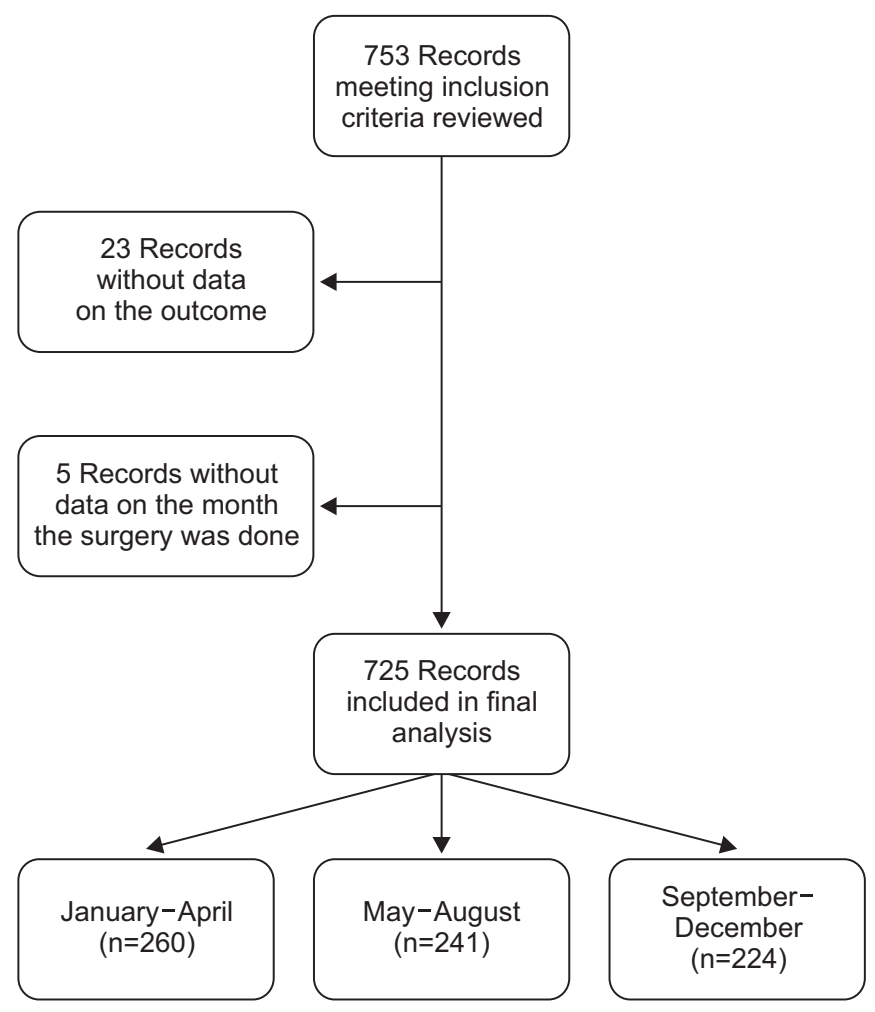

Fig. 1. Flowchart showing extraction of data. procedure. All patients underwent standard routine deep venous thrombosis (DVT) protocol. All patients underwent a standardized preoperative antibiotic protocol which was started an hour before surgery and continued for the next 24 hours. Intraoperatively, the incision site was cleaned using pyridine soap/solution before draping. All patients underwent a standard postoperative protocol in the inpatient ward including mobilization and physiotherapy. Knee range of motion and full weight bearing as tolerated was started postoperative day 1 for patients undergoing general anesthesia. For patients with regional/epidural anesthesia, knee range of motion exercises were started postoperative day 1 and full weight bearing as tolerated was started after the epidural catheter was removed. Of note, in our part of the country, a majority of the rehabilitation protocols are carried out while the patient is admitted in the ward as we do not have any rehabilitation/ recovery centers. This is one of the major reasons why our length of stay was prolonged as compared to our western counterparts. This is followed up by home physiotherapy sessions on an as needed basis. Patients were closely followed up after discharge for 30 days to monitor for any postoperative complications that might have developed.

\section{Methods}

Medical records were reviewed and noted on a pro forma basis. We recorded demographic data (age, gender, comorbidities, American Society of Anesthesiologists grade and date of surgery) and clinical data (type of surgery, total operative time [TOT], estimated blood loss, the need for postoperative transfusion, postoperative special care unit [SCU] stay, length of stay [from admission to discharge] and postoperative complications). Postoperative complications included major complicationsurinary tract infection (UTI), DVT, surgical site infection (SSI) and cardiac complications. The other variable was inpatient complications' which took into account overall postoperative complications including major complications (DVT, cardiac complication, SSI, UTI, sepsis, and stroke), moderate complications (delirium, pulmonary edema, and hypotension) and minor complications (deranged reflos, electrolyte imbalances, urinary retention and postoperative ileus). DVT was defined as symptomatic DVT based on the following criteria: edema, leg pain, tenderness, warmth/erythema and/or clinical symptoms of pulmonary embolism). Nadler formula was used to calculate the estimated blood volume of a person. Intraoperative blood loss was calculated using the Gross formula, which has been previously used for calculating blood loss in TKAs ${ }^{11}$. SCUs are nurseled inpatient care units usually managed by a team of nurses with 
a pulmonologist supervising and are different from intensive care units (ICU). Patients were admitted to the SCU based on their comorbidities and in case of any intraoperative hemodynamic changes that required aggressive monitoring postoperatively.

Month of surgery was extracted from the date and was appropriately set as a categorical variable with 1, January; 2, February; 3, March and so on. We then decided to divide the months into three trimesters of four months: 1 (January-April), 2 (May-August), and 3 (September-December). Comparative analyses were then carried out between these groups.

Length of stay and TOT were skewed according to both Kolmogrov-Smirnov tests and Shapiro-Wilk tests; therefore, the MannWhitney $U$-Test and Kruskal-Wallis test for nonparametric scale variables were used for the analysis of data. Pearson chi-square test was used for the analysis of categorical variables. Following crude analysis, binomial logistic regression was also carried out to adjust for significant variables associated with increased postoperative complications. For all statistical tests, the alpha value was set at 0.05 .

\section{Results}

A total of 725 patients who underwent TKA were included in the study. Out of the 725 patients, 113 (15.6\%) developed an inpatient complication. The highest percentage of complications with respect to months was seen in July at $35.6 \%$ (Fig. 2). Patient demographics and details on important specific complications are given in Table 1 .

Results showed that operations done during the months of May-August were associated with a significantly higher risk of

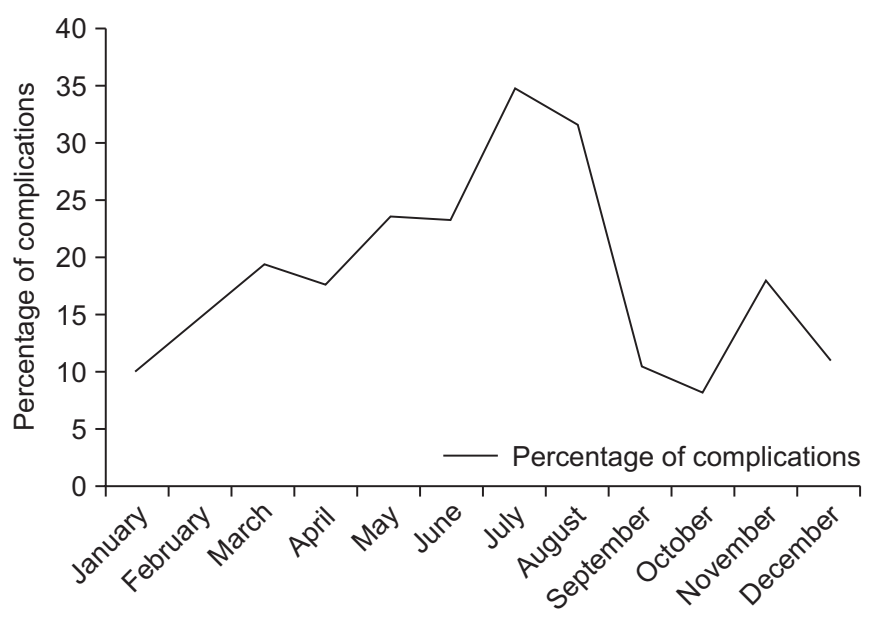

Fig. 2. Graph showing percentage of complications per month over a 10 year period. postoperative inpatient complications ( $\mathrm{p}=0.003$ ) (Table 2). Posthoc pairwise comparison showed that May-August surgeries were associated with a higher risk of postoperative complications when compared with both January-April and September-December $(\mathrm{p}<0.05)$. No association was present between summer surgeries and SSIs $(\mathrm{p}=0.486)$.

We also found a longer postoperative SCU stay was associated with surgeries performed earlier during the year. Binomial logistic regression was then conducted while adjusting for significant factors from the unadjusted analysis (Tables 3 and 4). Based on the findings, no association was found between surgeries done during the summer months and a longer length of stay $(\mathrm{p}=0.747)$.

After adjusting for significant factors, binomial logistic regression analysis showed that in a prediction model, summer surger-

Table 1. Patient Demographics

\begin{tabular}{lc}
\hline \multicolumn{1}{c}{ Variable } & Value \\
\hline Age (yr) & $62.4 \pm 9.7$ \\
Sex & \\
Male & $162(22.3)$ \\
Female & $563(77.7)$ \\
Bilateral knee surgery & $420(57.9)$ \\
Unilateral knee surgery & $305(42.1)$ \\
Comorbidities & \\
Diabetes mellitus & $198(27.3)$ \\
Hypertension & $424(58.4)$ \\
Asthma & $42(5.8)$ \\
Hyperthyroidism & $6(0.8)$ \\
Hypothyroidism & $42(5.8)$ \\
Coronary artery disease & $64(8.8)$ \\
Dyslipidemia & $23(3.2)$ \\
Chronic kidney disease & $19(2.6)$ \\
Chronic obstructive pulmonary disease & $3(0.4)$ \\
Hypercholesterolemia & $10(1.4)$ \\
Length of stay (day) & $8.97 \pm 2.97$ \\
Total operative time (min) & $210.3 \pm 73.8$ \\
Postoperative special care unit stay & $35(4.8)$ \\
Postoperative transfusion & $143(19.7)$ \\
Inpatient complications & $113(15.6)$ \\
Complications within 30 days & $20(2.8)$ \\
Surgical site infection & $7(1.0)$ \\
Urinary tract infection & $18(2.5)$ \\
Deep venous thrombosis & $10.1)$ \\
\hline
\end{tabular}

Values are presented as mean \pm standard deviation or number (\%). 
Table 2. Comparison among Groups Divided according to the Month of Surgery

\begin{tabular}{|c|c|c|c|c|}
\hline \multirow{2}{*}{ Variable } & Group I (n=260) & Group II (n=241) & Group III (n=224) & \multirow{2}{*}{ p-value } \\
\hline & January-April & May-August & September-December & \\
\hline Age (yr), mean \pm SD & $61.4 \pm 10.3$ & $63.4 \pm 8.9$ & $62.6 \pm 9.8$ & $0.116^{\mathrm{a})}$ \\
\hline Sex & & & & $0.642^{\mathrm{b})}$ \\
\hline Male & $62(23.8)$ & $54(22.0)$ & $46(20.4)$ & \\
\hline Female & $198(76.2)$ & $187(77.2)$ & $178(79.6)$ & \\
\hline Unilateral knee & $109(41.9)$ & $100(41.5)$ & $96(42.9)$ & $0.941^{\mathrm{b})}$ \\
\hline Bilateral knee & $151(58.1)$ & $141(58.5)$ & $128(57.1)$ & \\
\hline \multicolumn{5}{|l|}{ Comorbidities } \\
\hline Diabetes mellitus & $77(29.6)$ & $69(28.6)$ & $52(23.2)$ & $0.247^{\mathrm{b})}$ \\
\hline Hypertension & $156(60.0)$ & $143(59)$ & $125(55.8)$ & $0.564^{\mathrm{b})}$ \\
\hline Asthma & $15(5.8)$ & $15(6.2)$ & $12(5.4)$ & $0.923^{\mathrm{b})}$ \\
\hline COPD & 0 & $2(0.8)$ & $1(0.4)$ & $0.350^{\mathrm{b})}$ \\
\hline Hyperthyroidism & $1(0.4)$ & $2(0.8)$ & $3(1.3)$ & $0.513^{\mathrm{b})}$ \\
\hline Hypothyroidism & $13(5.0)$ & $19(7.9)$ & $10(4.5)$ & $0.228^{\mathrm{b})}$ \\
\hline Coronary artery disease & $23(8.8)$ & $23(9.5)$ & $18(8.0)$ & $0.849^{\mathrm{b})}$ \\
\hline Dyslipidemia & $10(3.8)$ & $9(3.7)$ & $4(1.8)$ & $0.362^{\mathrm{b})}$ \\
\hline Hypercholesterolemia & $3(1.2)$ & $2(0.8)$ & $5(2.2)$ & $0.401^{\mathrm{b})}$ \\
\hline Chronic kidney disease & $6(2.3)$ & $8(3.3)$ & $5(2.2)$ & $0.707^{\mathrm{b})}$ \\
\hline \multicolumn{5}{|l|}{ ASA grade } \\
\hline I & $12(4.6)$ & $11(4.6)$ & $14(5.8)$ & $0.265^{\mathrm{b})}$ \\
\hline II & $177(67.3)$ & $181(74.3)$ & $166(73.2)$ & \\
\hline III & $71(27.3)$ & $48(19.9)$ & $44(19.6)$ & \\
\hline IV & 0 & $1(0.4)$ & 0 & \\
\hline Median length of stay (day) & $9.0(7-10)$ & $8.0(7-10)$ & $8.0(7-10)$ & $0.747^{\mathrm{a})}$ \\
\hline Median TOT (min) & $209.5(144.25-260.8)$ & $212.5(146.75-260.5)$ & $222.5(145.0-263.25)$ & $0.872^{\mathrm{a})}$ \\
\hline Postop special care unit & $17(6.5)$ & $14(5.8)$ & $4(1.8)$ & $0.036^{\mathrm{b})}$ \\
\hline Postop transfusion & $53(20.4)$ & $53(22.0)$ & $37(16.5)$ & $0.315^{\mathrm{b})}$ \\
\hline Inpatient complications & $38(14.6)$ & $52(21.6)$ & $23(10.3)$ & $0.003^{\mathrm{b})}$ \\
\hline Complications within 30 days & $8(3.1)$ & $7(2.9)$ & $5(2.2)$ & $0.840^{\mathrm{b})}$ \\
\hline \multicolumn{5}{|l|}{ Major complications } \\
\hline Surgical site infection & $1(0.4)$ & $3(1.2)$ & $3(1.3)$ & $0.486^{\mathrm{b})}$ \\
\hline Deep venous thrombosis & 0 & $1(0.4)$ & 0 & $0.366^{\mathrm{b})}$ \\
\hline Urinary tract infection & $5(1.9)$ & $9(3.7)$ & $4(1.8)$ & $0.310^{\mathrm{b})}$ \\
\hline Cardiac complications & $9(3.5)$ & $4(1.7)$ & $3(1.3)$ & $0.222^{\mathrm{b})}$ \\
\hline
\end{tabular}

Values are presented as number (\%).

SD: standard deviation, COPD: chronic obstructive pulmonary disease, ASA: American Society of Anesthesiologists, TOT: total operative time, Postop: postoperative.

${ }^{a)}$ Kruskal-Wallis test for continuous variables.

${ }^{b)}$ Pearson chi-square test for categorical variables.

ies (odds ratio [OR], 2.13; 95\% confidence interval [CI], 1.18 to 3.85 ), postoperative transfusion (OR, 2.46; $95 \% \mathrm{CI}, 1.43$ to 4.26 ), postoperative SCU stay (OR, $4.68 ; 95 \% \mathrm{CI}, 1.99$ to 11.0$)$ and a preoperative comorbidity of chronic kidney disease (OR, 3.27; 95\% CI, 1.15 to 9.28) were associated with a higher odds of developing inpatient complications. Of note, patients who underwent 
Table 3. Unadjusted Analysis for Factors associated with Postoperative (Postop) Complications Using Pearson Chi-Square Test and MannWhitney $U$-Test

\begin{tabular}{|c|c|c|c|}
\hline Variable & $\begin{array}{c}\text { Postop } \\
\text { complications }\end{array}$ & $\begin{array}{c}\text { NO postop } \\
\text { complications }\end{array}$ & $\mathrm{p}$-value \\
\hline Age (yr) & $63.7 \pm 9.0$ & $62.2 \pm 9.8$ & $0.125^{\mathrm{a})}$ \\
\hline Sex & & & 0.471 \\
\hline Male & $28(24.8)$ & $132(21.7)$ & \\
\hline Female & $85(75.2)$ & $476(78.3)$ & \\
\hline Type of surgery & & & 0.046 \\
\hline Unilateral & $38(33.6)$ & $267(43.7)$ & \\
\hline Bilateral & $75(66.4)$ & $344(56.3)$ & \\
\hline Surgery done during & & & 0.003 \\
\hline Jan-April & $38(33.6)$ & $222(36.3)$ & \\
\hline May-August & $52(46.0)$ & $189(30.9)$ & \\
\hline September-December & $23(20.4)$ & $201(32.8)$ & \\
\hline \multicolumn{4}{|l|}{ Comorbidities } \\
\hline Diabetes mellitus & $42(37.2)$ & $156(25.5)$ & 0.010 \\
\hline Hypertension & $73(64.0)$ & $35(57.4)$ & 0.421 \\
\hline COPD & $1(0.9)$ & $2(0.3)$ & 0.396 \\
\hline Asthma & $10(8.8)$ & $32(5.2)$ & 0.130 \\
\hline Hyperthyroidism & 0 & $6(1.0)$ & 0.291 \\
\hline Hypothyroidism & $7(6.2)$ & $35(5.7)$ & 0.842 \\
\hline Chronic kidney disease & $8(7.1)$ & $11(1.8)$ & 0.001 \\
\hline Coronary artery disease & $13(11.5)$ & $51(8.3)$ & 0.275 \\
\hline Dyslipidemia & $1(4.3)$ & $22(3.6)$ & 0.131 \\
\hline Hypercholesterolemia & $2(1.8)$ & $8(1.3)$ & 0.698 \\
\hline ASA grade & & & 0.036 \\
\hline I & $2(1.8)$ & $34(5.6)$ & \\
\hline II & $75(66.4)$ & $443(73.2)$ & \\
\hline III & $36(31.9)$ & $127(21.0)$ & \\
\hline IV & 0 & $1(0.2)$ & \\
\hline Length of stay (day) & $9.67 \pm 3.4$ & $8.84 \pm 2.9$ & $0.003^{\mathrm{a})}$ \\
\hline Total operative time ( $\mathrm{min}$ ) & $221.6 \pm 74.1$ & $208.3 \pm 73.6$ & $0.093^{\mathrm{a})}$ \\
\hline Postop transfusion & & & 0.000 \\
\hline Yes & $41(36.3)$ & $102(16.7)$ & \\
\hline No & $72(63.7)$ & $510(87.6)$ & \\
\hline Postop special care unit & & & 0.000 \\
\hline Yes & $16(14.2)$ & $19(3.1)$ & \\
\hline No & $97(85.8)$ & $593(96.9)$ & \\
\hline
\end{tabular}

Values are presented as mean \pm standard deviation or number (\%). COPD: chronic obstructive pulmonary disease, ASA: American Society of Anesthesiologists.

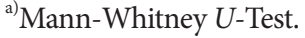

Table 4. Binomial Logistic Regression with Membership set "Yes" for Complications during Stay

\begin{tabular}{|c|c|c|}
\hline Variable & Odds ratio $(95 \% \mathrm{CI})$ & p-value \\
\hline \multicolumn{3}{|l|}{ Knee surgery } \\
\hline Unilateral & 1 & - \\
\hline Bilateral & $1.12(0.675$ to 1.86$)$ & 0.661 \\
\hline \multicolumn{3}{|l|}{ Diabetes mellitus } \\
\hline No & 1 & - \\
\hline Yes & 1.58 (0.97 to 2.57$)$ & 0.066 \\
\hline \multicolumn{3}{|l|}{ Chronic kidney disease } \\
\hline No & 1 & - \\
\hline Yes & 3.27 (1.15 to 9.28$)$ & 0.026 \\
\hline \multicolumn{3}{|l|}{ ASA grade } \\
\hline I & 1 & - \\
\hline II & $2.19(0.46$ to 10.4$)$ & 0.326 \\
\hline III & 3.15 (0.63 to 15.7$)$ & 0.162 \\
\hline IV & 1 & 1.0 \\
\hline Length of stay (day) & 1.05 (0.96 to 1.15$)$ & 0.315 \\
\hline \multicolumn{3}{|l|}{ Surgery done during } \\
\hline Jan-April & $0.98(0.53$ to 1.80$)$ & 0.947 \\
\hline May-August & $2.13(1.18$ to 3.85$)$ & 0.013 \\
\hline September-December & 1 & - \\
\hline \multicolumn{3}{|l|}{ Postop transfusion } \\
\hline No & 1 & - \\
\hline Yes & $2.46(1.43$ to 4.26$)$ & 0.001 \\
\hline \multicolumn{3}{|l|}{ Postop special care unit } \\
\hline No & 1 & - \\
\hline Yes & 4.68 (1.99 to 11.0$)$ & 0.000 \\
\hline
\end{tabular}

ASA: American Society of Anesthesiologists, Postop: postoperative.

surgery during May-August were twice more likely to suffer postoperative complications than those who did early during the year or in the winter months.

Patients who stayed in the postoperative SCU were five times more likely to experience postoperative complications than those who did not. Similarly, those who had chronic kidney disease were three times more likely to experience postoperative complications than those who did not.

\section{Discussion}

This study found that surgeries done during the peak summer months (May-August) in Pakistan were associated with a significantly higher risk of overall postoperative complications when compared to those performed early in the year or in the later 
winter months. However, the risk for SSIs and prolonged length of stay was not increased during the summer months (May-August).

There have been few researches regarding seasonal influences in surgical patients, and there are even fewer researches geared toward evaluating the influence specifically in the orthopedic population. Because the summer months in our western counterparts coincide with the 'July effect', it is difficult to find studies investigating whether the postoperative complications are occurring due to seasonality alone ${ }^{12-17)}$. Of point to note here is that this increase in postoperative complications is not the 'July effect' seen in many hospitals in the west. In the west, during the months of July there is an influx of new group of residents, fellows, nurses and physician assistants. Many studies done previously have shown that an influx of inexperienced staff have resulted in an increased morbidity and mortality during these months. However in our part of the world where medical schools usually finish their academic year in the last quarter of the year, new residents and interns usually join the hospitals starting January 1st of every year. Hence, while interpreting these results, it is advisable not to consider this effect the same as the 'July effect.'

No association was found between summer surgeries and SSI, DVT, cardiac complication and UTI. While performing an initial audit of the postoperative complications over the period of ten years, we noticed a sharp spike in the postoperative complications during the summer months. From an initial percentage of postoperative complications of $10 \%$ in January, it rose to an astounding $35.6 \%$ in July followed by a gradual decline and another small peak during the month of November. Of point to note here is that these postoperative complications included both major complications (DVT, cardiac complication, SSI, UTI, sepsis, and stroke), moderate complications (delirium, pulmonary edema, and hypotension) and minor complications (deranged reflos, electrolyte imbalances, urinary retension and postoperative ileus).

There could be multiple reasons responsible for this observed effect. During the summer months, a large number of attending staff, residents and ancillary support staff choose to leave for vacations. It is possible that there is a temporary outflux of wellexperienced staff who used to take care of patients during their stay and an influx of newer, less experienced staff who take over their duties temporarily. The staff that replaces the one off for vacation is usually less in number. Tourangeau et al. ${ }^{18)}$ found that for each additional mean year of nurse experience in the clinical unit, there were 4-6 fewer deaths for every 1,000 acute medical patients discharged. Similarly, Patrician et al. ${ }^{19)}$ also concluded that nursing skill and experience were both associated with adverse events. In addition, it is also possible that the staff is generally less satisfied during the summer months and more prone to making work-related accidents. Similarly, Lee et al. ${ }^{20)}$ and Rathert and $\mathrm{May}^{21)}$ showed that employee satisfaction was associated with a lower rate of medical errors.

Previous studies have shown that warmer temperatures and increased humidity both not only facilitate the colonization and replication of bacteria in the nosocomial environment but also increase colonization of the normal human flora. This inadvertently leads to a higher risk of SSIs ${ }^{7,22,23)}$. A previous study has shown that there is an increase in the incidence of SSIs during the summer months in patients undergoing total joint arthroplasty ${ }^{10)}$. However, our study showed no significant association between summer months and an increased risk of postoperative SSIs. Our findings are similar to those of Haws et al. ${ }^{8}$ who examined postoperative SSIs in patients undergoing fixation of fracture in summer months. They concluded that there was no association between summer months and surgical wound infections.

In a research published in 2011, Ackland et al. ${ }^{24)}$ conducted a study on 526 patients undergoing elective orthopedic surgery to see whether chronic kidney disease was associated with postoperative morbidity in orthopedic surgery. Their study found out that patients with chronic kidney disease sustained excess morbidity on day 5 , took longer to become morbidity-free and had a longer hospital length of stay. They also found out that chronic kidney disease patients sustained more pulmonary, infectious, cardiovascular, renal, neurologic and pain complications. These findings are similar to those seen in our study indicating that chronic kidney disease is an important preoperative risk factor that should be accounted for when planning operations.

Much has been researched regarding postoperative morbidity after allogenic transfusion, with a number of researches from different surgical fields indicating postoperative transfusion is associated with a longer length of stay, higher risk of infectious episodes, respiratory infections, sepsis, atrial fibrillation, acute renal failure and stroke $e^{25-28)}$.

Postoperative SCUs are specialized nurse-led inpatient care units. They are different from ICUs, with a pulmonologist usually overseeing the primary care of the patient. Being similar in structure to ICUs, we reviewed previous studies on ICU stay and their effect on postoperative morbidity. We found out that ICU stay was not only associated with an increased postoperative morbidity but also an increased risk of mortality ${ }^{29,30}$.

While there are some factors which cannot be controlled such as preoperative comorbidity of chronic kidney disease, several 
postoperative factors contributing to an increased risk of complications such as postoperative transfusion and postoperative SCU stay can be taken into account during preoperative planning. Identifying the risk factors associated with these variables can be used to sort out patients who might have an increased risk of complications and an appropriate care plan can be drafted up early in the course to deal with it.

This study has several limitations and these results should be interpreted with caution. Firstly, this study is a non-randomized retrospective study in nature. The variable postoperative complication was coded to contain both major, moderate and minor complications during the patient stay. Though we were able to retrieve major complications such as DVT, UTI, cardiac complication and SSI from file review, we could not take into account the minor complications separately. Our study did show that surgery during the summer months was not associated with a higher odds of major complications, but overall there was an increased risk of both major and minor complications. No root cause analysis was done to further investigate the reason for such phenomenon as that was not the main purpose of the study.

This study showed that the summer season was not associated with SSI. However, considering the limited sample size, one should be cautious about making conclusions as with a small incidence of SSIs in the population there is a risk of a type II error taking place. Also, the TKAs were performed by multiple different surgeons, which may introduce a risk of bias as different surgeons may have different preferences with respect to surgical approaches etc.

This study also shines light on another important research question which needs to be addressed in future studies: staff satisfaction and work-related accidents during the summer months. It is possible that the results from such researches may give an insight into a risk factor that is controllable and minimize the risk of postoperative complications occurring due to poor delivery of care and work-related accidents.

Further investigation into seasonality and its effect of postoperative complications and infections in particular is warranted. A much larger study involving various surgical subspecialties may yield a more definitive answer to this question.

\section{Conclusions}

The results of this study show that overall complication rates following TKAs exhibit a seasonal trend, with a peak during the summer months. Using a large sample size over a ten year period, our results may have some implication in clinical practice and stricter approaches to hospital guidelines during the summer months. Since there was no major association between major complications (DVT, SSI, cardiac complication, and UTI) and surgeries during the summer months, it is possible that a majority of these moderate and minor complications are occurring primarily due to work-related accidents during the summer months. Since even minor complications (electrolyte disturbances and urinary retention) cause significant distress to the patient's family, it is advisable that all possible causes leading to this phenomenon need to be thoroughly researched and addressed.

\section{Conflict of Interest}

No potential conflict of interest relevant to this article was reported.

\section{References}

1. Anderson JG, Wixson RL, Tsai D, Stulberg SD, Chang RW. Functional outcome and patient satisfaction in total knee patients over the age of 75. J Arthroplasty. 1996;11:831-40.

2. Hawker G, Wright J, Coyte P, Paul J, Dittus R, Croxford R, Katz B, Bombardier C, Heck D, Freund D. Health-related quality of life after knee replacement. J Bone Joint Surg Am. 1998;80:163-73.

3. Fortin PR, Clarke AE, Joseph L, Liang MH, Tanzer M, Ferland D, Phillips C, Partridge AJ, Bélisle P, Fossel AH, Mahomed N, Sledge CB, Katz JN. Outcomes of total hip and knee replacement: preoperative functional status predicts outcomes at six months after surgery. Arthritis Rheum. 1999;42:1722-8.

4. Dasenbrock HH, Clarke MJ, Thompson RE, Gokaslan ZL, Bydon A. The impact of July hospital admission on outcome after surgery for spinal metastases at academic medical centers in the United States, 2005 to 2008. Cancer. 2012;118: 1429-38.

5. Englesbe MJ, Pelletier SJ, Magee JC, Gauger P, Schifftner T, Henderson WG, Khuri SF, Campbell DA. Seasonal variation in surgical outcomes as measured by the American College of Surgeons-National Surgical Quality Improvement Program (ACS-NSQIP). Ann Surg. 2007;246:456-62.

6. Young JQ, Ranji SR, Wachter RM, Lee CM, Niehaus B, Auerbach AD. "July effect": impact of the academic year-end changeover on patient outcomes: a systematic review. Ann Intern Med. 2011;155:309-15.

7. Durkin MJ, Dicks KV, Baker AW, Lewis SS, Moehring RW, 
Chen LF, Sexton DJ, Anderson DJ. Seasonal variation of common surgical site infections: does season matter? Infect Control Hosp Epidemiol. 2015;36:1011-6.

8. Haws BE, Braun BM, Creech TB, Barnard ER, Miller AN. Is there a seasonal influence on orthopaedic surgical wound infection rates? J Surg Orthop Adv. Fall 2016;25:172-5.

9. Shuhaiber JH, Goldsmith K, Nashef SA. The influence of seasonal variation on cardiac surgery: a time-related clinical outcome predictor. J Thorac Cardiovasc Surg. 2008;136:8949.

10. Kane P, Chen C, Post Z, Radcliff K, Orozco F, Ong A. Seasonality of infection rates after total joint arthroplasty. Orthopedics. 2014;37:e182-6.

11. Gross JB. Estimating allowable blood loss: corrected for dilution. Anesthesiology. 1983;58:277-80.

12. Hoashi JS, Samdani AF, Betz RR, Bastrom TP; Harms Study Group, Cahill PJ. Is there a "July effect" in surgery for adolescent idiopathic scoliosis? J Bone Joint Surg Am. 2014;96:e55.

13. Inaba $K$, Recinos $G$, Teixeira PG, Barmparas G, Talving P, Salim A, Brown C, Rhee P, Demetriades D. Complications and death at the start of the new academic year: is there a July phenomenon? J Trauma. 2010;68:19-22.

14. Lesar TS, Briceland LL, Delcoure K, Parmalee JC, MastaGornic V, Pohl H. Medication prescribing errors in a teaching hospital. JAMA. 1990;263:2329-34.

15. Phillips DP, Barker GE. A July spike in fatal medication errors: a possible effect of new medical residents. J Gen Intern Med. 2010;25:774-9.

16. Ravi P, Trinh VQ, Sun M, Sammon J, Sukumar S, Gervais MK, Shariat SF, Kim SP, Kowalczyk KJ, Hu JC, Menon M, Karakiewicz PI, Trinh QD. Is there any evidence of a "July effect" in patients undergoing major cancer surgery? Can J Surg. 2014;57:82-8.

17. Schroeppel TJ, Fischer PE, Magnotti LJ, Croce MA, Fabian TC. The "July phenomenon": is trauma the exception? J Am Coll Surg. 2009;209:378-84.

18. Tourangeau AE, Giovannetti P, Tu JV, Wood M. Nursingrelated determinants of 30-day mortality for hospitalized patients. Can J Nurs Res. 2002;33:71-88.

19. Patrician PA, Loan L, McCarthy M, Fridman M, Donaldson N, Bingham M, Brosch LR. The association of shift-level nurse staffing with adverse patient events. J Nurs Adm. 2011; 41:64-70.

20. Lee DH, Lee SM, Schniederjans MJ. Medical error reduction: the effect of employee satisfaction with organizational support. Serv Ind J. 2001;31:1311-25.

21. Rathert C, May DR. Health care work environments, employee satisfaction, and patient safety: care provider perspectives. Health Care Manage Rev. 2007;32:2-11.

22. Dailiana ZH, Rigopoulos N, Varitimidis SE, Poultsides L, Petinaki E, Malizos KN. Clinical and epidemiological features of upper-extremity infections caused by Staphylococcus aureus carrying the PVL gene: a four-year study in Greece. Med Sci Monit. 2008;14:CR511-4.

23. Tong SY, Steer AC, Jenney AW, Carapetis JR. Communityassociated methicillin-resistant Staphylococcus aureus skin infections in the tropics. Dermatol Clin. 2011;29:21-32.

24. Ackland GL, Moran N, Cone S, Grocott MP, Mythen MG. Chronic kidney disease and postoperative morbidity after elective orthopedic surgery. Anesth Analg. 2011;112:137581.

25. Bower WF, Jin L, Underwood MJ, Lam YH, Lai PB. Perioperative blood transfusion increases length of hospital stay and number of postoperative complications in non-cardiac surgical patients. Hong Kong Med J. 2010;16:116-20.

26. Hill GE, Frawley WH, Griffith KE, Forestner JE, Minei JP. Allogeneic blood transfusion increases the risk of postoperative bacterial infection: a meta-analysis. J Trauma. 2003;54: 908-14.

27. Mikkola R, Gunn J, Heikkinen J, Wistbacka JO, Teittinen K, Kuttila K, Lahtinen J, Juvonen T, Airaksinen JK, Biancari F. Use of blood products and risk of stroke after coronary artery bypass surgery. Blood Transfus. 2012;10:490-501.

28. Kawai M, Takeda M, Tsugawa Y, Tofuku Y, Takeda R, Kitou C, Mori T. Hemolytic anemia and acute renal failure caused by blood transfusions. Rinsho Ketsueki. 1990;31:1706-10.

29. Abelha FJ, Castro MA, Landeiro NM, Neves AM, Santos CC. Mortality and length of stay in a surgical intensive care unit. Rev Bras Anestesiol. 2006;56:34-45.

30. Siddiqui S. Mortality profile across our intensive care units: a 5-year database report from a Singapore restructured hospital. Indian J Crit Care Med. 2015;19:726-7. 